\title{
UTSTILLINGEN SOM DOKUMENTASJONSFORM I MODERNE OG POSTMODERNE TIDER
}

\section{Hilde Gaard}

Dokumentasjonsformer er definert som dokumentasjonsvitenskapens objekt. Museumsutstillingen kan oppfattes som en slik dokumentasjonsform som kan illustreres gjennom det tresidige forhold mellom hvordan et felt eller fenomen blir representert ved hjelp av bestemte medier $p a ̊$ en bestemt måte eller tradisjon. Utstillingsformen er i dette tilfellet et konkret uttrykk for en dokumentasjonsform. Videre kan man prøve à dele inn utstillingsformene i forskjellige kategorier der man identifiserer noen utstillingsformer basert på visse kriterier.

Et problem er å bestemme hvilke kriterier inndelingen skal basere seg på. Man kan tenke seg mange forskjellige kriterier:

* målsetning/kommunikative mål

* medium

* historisk

* disiplin/fag

* prinsipp

Å skille mellom moderne og postmoderne utstillinger kan være en måte å klassifisere utstillingsformene på. Man kan altså dele utstillingen inn i noen former, men det blir straks mer problematisk hvis vi skal utlede betydningen av valg av form. Fører en bestemt måte å ordne materialet på til noen betydninger, men hindrer andre? Det faktum at man stadig får nye måter å ordne og dokumentere på, betyr det at alle kunnskapsorganiseringer er sosialt konstruert i steden for «sann» eller «rasjonell»? Og hva er det utstillingen dypest sett dokumenterer?

Utstillingen som sådan er også en ganske problematisk størrelse. Utstillingsteknikker som interiørdesign, montre, lyssetting, tekst og typografi, bruken av illusjonsskapende effekter generelt, blir på mange måter betraktet som "usynlige», ganske enkelt midler som tillater gjenstandene å «snakke for seg selv». Derfor har denne dokumentasjonsformen forblitt stort sett uutforsket. I sin skyggetilværelse blant andre medier er den foreløpig ikke funnet interessant nok til at man har utviklet en kritikk av utstillingsspråket på 
64 linje med den som blir anvendt på filmen og boka.

Fra det moderne eller offentlige museet oppstod på 1800-tallet, det vil si fra det ble åpnet for et bredere, allment publikum, er det blitt etablert en rekke utstillingstradisjoner som i den grad nå tas for gitt at de ikke registreres som valgte former.

\section{MODERNE OG MODERNITET}

Men for å kunne si noe om utstillingen i moderne tider må vi først se litt på begrepshistorien til uttrykk som moderne og modernitet. Det paradoksale med begrepet om det moderne er at det er av forholdsvis gammel dato. Ordet «moderne» \ble først brukt sent på 400-tallet for å avgrense den kristne samtid overfor den hedensk-antikke fortid. I opplysningstidens forestilling om menneskehetens uendelige framskritt mot det stadig fornuftigere og moralsk bedre, løsriver begrepet seg fra sin relasjon til antikken (BøRygg, 1982:36). I historievitenskapen er moderne tider det som etterfulgte middelalderen, mens i filosofien er det moderne knyttet til Descartes og oppkomsten av moderne vitenskap. Dette er igjen forbundet med opplysningstiden. Hegel sa at det moderne samfunn var et samfunn hvis verdier var adskilt i overensstemmelse med temaene i Kants kritikk: vitenskap, kunst og moral. Heidegger mente derimot at modernitet var subjekt-objekt tenkning.

Men denne filosofisk-sosiologiske modernitet må ikke forveksles med ideen om moderne kunst; en bevegelse av skoler og retninger fra midten av forrige århundre fram til etterkrigstiden. Det moderne innen kunsten innledes med Baudelaire og
Manet på 1800-tallet, ikke Descartes eller Kant på 16-1700-tallet. Man kan si at starten var Baudelaires proklamering av det nylagede substantivet modernité og Rimbauds imperativ om å være absolutt moderne («Il faut être absolument moderne»). Begrepet går da fra å være en temporell bestemmelse eller tidslig avgrensning til å få normativ karakter. Moderne kunst blir paradoksalt nok oppfattet som en slags negering av det moderne samfunn med dets rasjonalitet og framskrittstro.

\section{OBJEKTUTSTILLING OG DIORAMA}

Det er spesielt to prinsipp for kunnskapsorganisering som hadde sitt opphav i det moderne museet, nemlig objektrettede utstillinger og diorama/interiørutstillinger. Den objektrettede utstillingen tar utgangspunkt i gjenstanden og framhever denne som visuelt sentrum. Artefaktene i seg selv er det viktigste. Kunstmuseene er en typisk eksponent for denne typen utstilling, mens de eldre kronologiske og typologiske utstillingene med «de tusen pilespissene» er en annen variant. Dette prinsippet kalles også det estetiske eller vitenskapelige prinsipp.

Dioramautstillingen søker derimot å gjenskape et miljø eller interiør der perspektivet er rettet mot helheten. I steden for en estetisk eller vitenskapelig tilnærming brukes ulike medier og teknikker $\mathrm{i}$ en levendegjørelse som til sammen utgjør en fortelling. Det er særlig i natur- og kulturhistoriske museer man finner denne typen.

Begge disse prinsippene baserte seg på teorier om evolusjon, men representerer to ulike strategier for å dokumentere dette. Utviklingstanken, ideen om tiden og his- 
torien som en endeløs utvikling, slår på 1800-tallet gjennom på alle felt. Tidens gang blir oppdelt i store tidsrom, tidsaldre og epoker. Forhistorien inndeles i stein-, bronse- og jernalder. De etnografiske museenes formål blir å vise menneskeslektens dannelseshistorie og kunstmuseene forlater de rent dekorative opphengningsprinsipp til fordel for utviklingsrekken.

Modernitet ble videre knyttet til troen på at en objektiv, sann virkelighet eksisterte og at alle mennesker kunne ta del i denne gjennom museets unike evne til å stille ut og demonstrere hvordan verden fungerte. Det som adskilte Europa fra andre kulturer var nettopp dynamikk, utvikling og konstant fornyelse. Det ble satt i kontrast til den ro, treghet og begrensninger som karakteriserte andre kulturer. Man kan si at utstillingen ble en typisk eksponent for det moderne, europeiske, kulturelle uttrykk. Og troen på at kunnskap kan stilles ut og legges fram $\mathrm{i}$ et temporalt og tredimensjonalt rom, og at dette er moralsk ønskelig og fremmer utviklingen av ny kunnskap, er i seg selv en moderne metafortelling. Som dokumentasjonsform er utstillingen i så måte et like karakteristisk utslag i tiden som den trykte boka eller internett. Det er tvilsomt om den typologiske metoden kunne bli forstått eller kunne sies å eksistere i det hele tatt, uten denne oppstilling av gjenstander i montre og skap. Denne typen kunnskap og dets demonstrasjon i utstillingen går ut på det samme.

Teknologi og media assosiert med denne kunnskapen basert på klassifikasjon og ordning bidro sterkt til at den fikk masse, tetthet. På slutten av 1800-tallet ble glass, som utstillingmontrenes suksess var så avhengig av, tilgjengelig $\mathrm{i}$ relativt store størrelser og av god kvalitet. Forut for dette var glasset håndblåst og håndpolert $\mathrm{i}$ små størrelser. Alle skap hadde sprosser som i vanlige vinduer og glassoverflaten var så ugjevn at gjenstandene måtte tas ut for å kunne studeres i detalj. Med den forbedrede glassteknologien kunne skap og montre stilles i lange rekker for å demonstrere det klassifikatoriske og typologiske regimet.

\section{PITT RIVERS}

Pitt Rivers samling i Oxford var den første utstillingen hvor systematisk klassifikasjon ble overført til et etnografisk materiale. Han baserte seg på to fundamentale prinsipp. For det første at materiell kultur avslører menneskehetens essensielle natur og utvikling. For det andre at utviklingen av artefakter, og dermed den menneskelige natur, følger darwinistiske prinsipper, slik at typene utvikler seg gjennom en prosess av naturlig utvelgelse. Hele denne strukturen kunne rekonstrueres ved utstillingen av gjenstander som dokumenterte forskjellige kulturelle nivå oppnådd av ulike grupper og folk. Rivers publiserte sitt syn på utstillingen i The Evolution of Culture i 1875.

Denne måten henvender seg først og fremst til fagmannen og må sies å være ganske ekskluderende. Allerede i samtiden ble det kritisert som utstillingsprinsipp. August Strindberg latterliggjorde den typologiske metoden i den lett fordekte sammenligningen med kvasi-vitenskapen «knappologi». Knappologi var vitenskapen om knapper. Begrepet ble brukt i betydningen «systematisering av verdiløse fakta med vitenskapelig anspråk.» Professor Hylling i Strindbergs "De lycksaligas $\varnothing$ " 
66 satte seg fore å ordne all verdens knapper: små knapper, store knapper, brune knapper, svarte knapper, knapper av tre, knapper av metall, knapper av lær, knapper med to hull, knapper med fire hull, skjorteknapper, bukseknapper osv, osv, i et absurd totalunivers av det ordnende prinsipp knapper. Denne satiren gir imidlertid en gjenkjennelig beskrivelse av den arkeologiske utstillingen i Statens Historiska Museum på slutten av 1800-tallet.

\section{ARTUR HAZELIUS}

Men når det dreide seg om noe så viktig som utviklingslæren, som skulle utbre den oppfatningen at europeerne sto øverst på utviklingsstigen, så foretrakk de etnografiske museene etterhvert en mer utadvendt og populær framstillingsmåte. Gjenstandene ble ført sammen til en helhet i tidstypiske miljøer, slik at de utgjorde en liten fortelling. Dette prinsippet tenderer mot fiksjonen og var inspirert av vokskabinettene, tableaux vivants og dioramaene som var en stor suksess på verdensutstillingene. Artur Hazelius regnes som en av de første til å benytte seg dette prinsippet i utstillingene han arrangerte i Skandinavisketnografisk samling i Stockholm 1873 og deretter i sitt friluftsmuseum Skansen 1891.

I 1878 deltok Sverige ved verdensutstil- lingen i Paris med Hazelius' samlinger. Hans utstillingsideer må karakteriseres som nyskapende. I «levende» tablåer plasserte han gjenstander og voksfigurer i et rekonstruert miljø mot et panorama av ulike landskap. Det kunne minne om Düsseldorf-malernes folkelivsgenrer, lett sentimentalt og romantiserende. Han imiterte teateret med blant annet å sette fram stoler foran sine tablåer, som lignet ulike scener $i$ et teaterstykke, og han ordnet sine dokker som en regissør arrangerer sine aktører på scenen. Dette var museet som totalteater, en dramatisering av menneskehetens utvikling.

For Hazelius var det viktig at de besøkende lett skulle kunne leve seg inn i scenemiljøet og atmosfæren. Han henvendte seg primært til et allment publikum. I 1893 gikk han et steg videre i sin streben etter den realistiske og virkelighetsnære utstillingen. Han lot en sameleir fra Jokkmokk med folk og alt flytte til Skansen. Denne utstillingen var høyst sannsynlig inspirert av verdensutstillingen i Paris 1889, hvor de installerte fremmede folkegrupper i «ekte» landsbyer og de ble bedt om å "opptre» med sitt hverdagsliv. Disse "primitive hedningene» var representanter på den tidligste utviklingen av menneskeheten, skjæringspunktet mellom natur og kultur, "the missing link» mellom aper og mennesker.

\begin{tabular}{|c|c|}
\hline Pitt Rivers & Artur Hazelius \\
Objektorientert & Diorama/interiør \\
\hline Vitenskapelig analyse & Folkelig pedagogisk fortelling \\
Distanse, ekskluderende & Nærhet, inkluderende \\
Enkeltobjekt & Helhet \\
Formalistisk & Kontekstualistisk \\
Estetikk & Levendegjørelse \\
\hline
\end{tabular}


Det er ingen tvil om at beslutningen om å forlate det formalistiske, kunsthistoriske, vitenskapelige og objektsentrerte prinsipp til fordel for kontekstuelle og funksjonalistiske prinsipp var en viktig innovasjon. Dette bekreftes blant annet gjennom den enorme økningen i utstillinger med dette utgangspunkt. Disse «levende bildene» og rekonstruksjonene har satt spor i all påfølgende utstillingsaktivitet innen kulturfagene.

\section{OM POSTMODERNISMEN}

Postmodernismen er ikke en enhetlig filosofisk eller kunstnerisk bevegelse. Det postmoderne er gjerne en betegnelse for en rekke delvis forbundne oppbrudd og nyorienteringer innen åndslivet etter annen verdenskrig, og da både som en videreføring av modernismetradisjonen, men også som et oppgjør med den. Betegnelsen viser oftest til en tilstand eller kultursituasjon som et historisk vilkår, og en holdning som kan leses i kulturytringene.

Den moderne, avantgardistiske kunstens krav om å være nyskapende eller absolutt moderne hadde redusert kunsten til dens mest grunnleggende eller primitive element, og på den måten uttømt alle muligheter for videre innovasjon. Alt som er tilbake er flat reproduksjon og blanding av tidligere stiler. På samme måte som postmoderne kunstnere tilegner seg og resirkulerer stiler, så overdrar og annekterer postmoderne teori ideer og begreper. Ribbet for sin opprinnelige kontekst blir ideene og begrepene overførbare, de migrerer. Man står fritt til å bruke hvilke som helst teorier som tjener ens hensikter uten hen- syn til tradisjon eller sammenheng. Postmoderne teori blir sammenlignet med en slags ideenes Toyota: produsert og satt sammen på mange forskjellige steder og siden solgt over alt (Rajchman, 1991: 125).

I korthet satte postmodernismen spørsmålstegn ved muligheten for oppdagelsen av sannhet og fakta, samt forfatterens legitimitet. Det postmoderne betegner kulturtilstanden i vårt høyteknologiske informasjonssamfunn, kjennetegnet ved oppløsningen av de store, sammenhengende tilværelsesfortolkningene som framskrittstroen og utviklingslæren. En helhetsforståelse er ikke lenger mulig $i$ en tilstand hvor språklige og kulturelle uttrykk sirkulerer uten henvisning til en felles sannhet, men bare refererer til seg selv. Denne utviklingen har delvis opphav i framveksten av massemedia og massekommunikasjon, fortrinnsvis TV'n og datamaskinen. Disse mediene har bidratt til å viske ut grensene mellom «finkultur»/kunst og reproduksjoner/kitsch og bidratt til en homogenisering av kultur.

Det er likevel noen karakteristika som postmoderne teoretikere kan enes om som kjennetegner den postmoderne tilstand. Det som gjerne framheves er bildets, framtoningens og overflate-effektens dominans over dybde (de spør f.eks. om Ronald Reagan var president eller en Bfilm skuespiller, virkelig eller pappfigur, levende eller "spitting image»?) Det er utviskningen av grensen mellom representasjon og virkelighet (var Gulf-krigen virkelig eller en media-happening?) $\mathrm{Og} \operatorname{det}$ er en forrang for parodi, nostalgi, kitsch og pastisj framfor mer postitivt ladede representasjonsmåter som realisme og naturalisme (Wilson, 1990:401). 


\section{TRE UTSTILLINGSFORMER}

Av det jeg vil kalle postmoderne utstillinger har jeg identifisert minst tre forskjellige former

\section{- DEN SELVREFLEKSIVE}

Den selvrefleksive, representert ved Fluffs \& Feathers, var en utstilling ved Royal Ontario Museum i Canada i 1992. I følge den indianske konservatoren Deborah Doxtator var utstillingen laget spesielt for lokale indianersamfunn for å vise og bevisstgjøre disse hvordan stereotype representasjoner av innfødte er blitt produsert gjennom blant annet museer. Når så denne nettopp blir flyttet inn i et etablert vestlig museum skaper dette sine egne utilsiktede ironier. Vi får paradokset som Doxtator uttrykker det: "The Royal Ontario Museum trying to represent us represent them.» (Macdonald/Fyfe, 1996: 95).

Slik jeg oppfatter det er Fluffs \& Feathers en parodi eller pastisj over den moderne utstillingen. Den begynner nokså tilforlatelig og tradisjonelt med gjenkjennelige indianske gjenstander i et glassmonter. De besøkende som har vært innom de andre utstillingene i museet tenker at her har de nok en kultur de kan se og fortære visuelt.

Dette blir umiddelbart utfordret i den neste seksjonen hvor det skapes et inntrykk av at gjenstandene er totalt vilkårlig arrangert. Historiske gjenstander er plassert uten noen tilsynelatende kronologisk eller tematisk orden, tomme vegger står i kontrast til overfylte områder. Samtidig er ekte, autentiske, lokale produkter kontrastert med masseproduserte forbruksvarer og reproduksjoner som cd-plater, filmpla- kater, totempeler i plast og leketøysindianere. På denne måten trer utstillingsmekanismene fram i lyset. Den setter spørsmålstegn ved skillet mellom moderne, materiell forbrukskultur på den ene siden og det ekte indianske plassert i fortiden på den andre. Hensikten er å hindre besøkeren $i$ å tre tilbake til en eller annen udefinert fortid for å nyte en annen kultur. Utstillingen illustrerer med dette på eksemplarisk måte det postmoderne som en postkolonial verden av produkter som er produsert og solgt på mange forskjellige steder uten et sentrum. De trivielle gjenstandene er nære, familiære og demystifisert, i motsetning til det moderne museets prosess med å «sakralisere» gjenstander til hellige objekt $i$ et turist-rituale. Indianerne er således ikke forsøkt eksotisert gjennom en distanse i tid og rom til hvite, vestlige folk.

Midt i utstillingen finner man utskjærte pappfigurer av en høvding og hans familie stilt opp mot et kunstig og glorete malt landskap, med klar referanse etter min mening til de pittoreske og lett sentimentale dioramautstillingene. De besøkende kan prøve på ulike indianske klær og posere i sitt indianerkostyme ved dette tablået som er reflektert $\mathrm{i}$ et stort speil. Poenget er å framkalle en refleksiv distanse hos publikum til sine egne erfaringer og stereotype oppfatninger. Det er nå helt klart at dette ikke er en etnografisk utstilling om en kulturell kategori, «indianere», men heller om hvordan stereotype representasjoner av andre skapes, og hvordan det føles å få slike negative stereotypier tilskrevet seg selv.

Siste del av utstillingen er et temmelig kontant uttrykk for det selvrefleksive. Den består av en serie fotografier i øyenhøyde 


\begin{tabular}{|c|c|c|}
\hline $\begin{array}{c}\text { Fluffs \& Feathers } \\
\text { Selvrefleksiv }\end{array}$ & $\begin{array}{c}\text { Vikingmuseet Borg/Holocaust } \\
\text { Memorial Museum } \\
\text { Prosessorientert formidling }\end{array}$ & Multimedial/digital \\
\hline $\begin{array}{c}\text { Erkjennelse } \\
\text { Verfremdung } \\
\text { Kultur som prosess } \\
\text { Selvrefleksiv }\end{array}$ & $\begin{array}{c}\text { Innlevelse } \\
\text { Illusjonsbefordring } \\
\text { Statisk, fjernt fra våre liv } \\
\text { Simulacrum }\end{array}$ & $\begin{array}{c}\text { Fragmentert } \\
\text { "Forfatterens død" }\end{array}$ \\
\hline
\end{tabular}

av innfødte folk, et par perlebesatte sko og en fjærbesatt underskjorte. Det siste er ikke et bilde, men rett og slett et speil hvor man konfronteres med sitt eget ansikt. Symbolsk overlates besøkeren til seg selv og sine oppfatninger av indianere. I steden for å moralsk fordømme det forkastelige ved stereotypier inviteres besøkeren til å delta $\mathrm{i}$ en dialog med en annen identitet, for om mulig à erfare på kroppen hvordan det føles å bli stereotypisert.

Slik jeg oppfatter det setter postmoderne utstillinger som Fluffs \& Feathers spørsmålstegn ved muligheten for å kunne representere virkeligheten eller historien i det hele tatt. Historie blir av mange poststrukturalister betraktet som nok et element i modernismens forsøk på å utvikle rigide metafortellinger hevet over kritikk. Med historiens slutt finnes det bare representasjoner og det gjør det nødvendig med en refleksjon og bevisstgjøring omkring de mimetiske grepene. Et påtakelig trekk ved Fluffs \& Feathers er nettopp representasjonene av representasjoner av representasjoner (f.eks fotokopier som viser hvordan hvite folk representerer innfødte innenfor museets eget representasjonssystem). Den problematiserer museets dominerende representsjonsstrategier ved å representere dem.

\section{DEN PROSESSORIENTERTE}

Det «levende museet» eller prosessorientert formidling mener jeg kan oppfattes som en postmoderne videreførelse av Hazelius' prinsipper om levendegjørelse og illusjonsbefordring. De er ikke uten en viss likhet med verdensutstillingenes negerlandsbyer og utstillingen av levende samer. På vikingmuseet Borg i Lofoten kan du ta på deg «ekte» vikingklær, smake husfruens kokkekunst eller ta deg en tur med høvdingens langskip. Du beveger deg $i$ et tilnærmet fullstendig simulert tidsbilde av vikingtiden, en hypervirkelighet der det virkelige og autentiske blir overflødig. Den prøver ikke å opprettholde distinksjonen mellom representasjon og virkelighet. Dette sammenfaller i høy grad med Jean Baudrillards simulacrum-begrep, som oppstår når distinksjonen mellom tegnet og det det refererer til i den virkelige verden bryter sammen. Moderne oppfatninger om mening og betydning er gått tapt og erstattet av en postmoderne nostalgi hvor vi søker fortiden gjennom våre egne klisjeaktige bilder av fortiden som for alltid er utenfor rekkevidde. Publikum har ikke noe grunnlag til å vurdere gyldigheten av det de ser, dets forhold til virkeligheten, enten det nå er korrekt eller ikke.

Holocaust Memorial Museum i Was- 
70 hington D.C tilbyr en annen slags hypervirkelig «Disneyland-tur» til fortiden - en temapark vandring gjennom jødeutryddelsene. Som besøker får du et ID-kort med navn og bilde av et virkelig holocaustoffer som matcher din alder og ditt kjønn. Du blir guidet gjennom ghettoen, utryddelsesleirene og ovnene der Zyklon$B$ gassens ofre ble brent. Du kjenner stanken fra hauger av skolær i oppløsning. Alt er ledsaget av historiske filmopptak. Ved å stikke ID-kortet i datastasjoner som er spredt rundt i lokalene får du vite hvordan ditt personlige subjekt klarer seg. Spenningen ligger i om du vil bli reddet, skutt, gasset eller brent. Når din hypervirkelige tur er over slenges ID-kortene i søpla sammen med annet rask. Spørsmålet er om du virkelig kan sies å ha opplevd Holocaust? Og hvem vil egentlig oppleve det?

Disse utstillingenes hovedmål er identifikasjon og etterligning; den eksakte reproduksjonen av fortidens materielle overflate. Dialektikken mellom virkelighet og fantasi er truet av simulacrumet.

Den postmoderne fortiden er en fortid hvor alt er mulig, hvor fantasi er potensielt like virkelig som historie. Vekten er lagt på autentisitet med hensyn til form, snarere enn autentisitet med hensyn til innhold. Publikum kan vandre rundt i dette miljøet og plukke opp det han eller hun finner tiltalende eller nyttig. Felles for vikingmuseet Borg og Holocaust M.M er opprettelsen av et kunstig og isolert sted. Ikke bare kunstig i betydningen av at de ikke bruker ekte bygninger eller gjenstander, men også at de konstruerer uvirkelige, mytologiske steder. I motsetning til det navnet denne typen formidling har fått, prosessorientert, så er slike utstillinger gjerne uinteressert i histo- riske prosesser. Borg er et fantasi-sted som tar «time-out» fra historien.

Slike selvrefleksive utstillinger som Fluffs \& Feathers skiller seg klart fra prosessorientert formidling ved å utvikle en kritisk kommentar til forestillingen om en ubevegelig og autentisk kultur. Det dras ingen skiller mellom en ekte, ren kultur i fortiden og en uekte, forurenset nåtid. Kanskje Fluffs \& Feathers viktigste bidrag var å representere kultur som prosess?

Felles for prosessorientert formidling er ideen om empati, innlevelse, forestillingen om museet som en tidsmaskin som skal bidra til en forståelse av andre. Fluffs \& Feathers gir til å begynne med inntrykk av å fortelle noe om «de andre» og den følger illusjonen et stykke på veien, før den sprekker som en ballong og punkterer opplevelsen av autentisitet, realisme, helhet osv. Teknikken kan minne om Bertold Brechts episke teater der begrepet Verfremdung står sentralt. Han kunne la publikum gli inn $\mathrm{i}$ illusjonen av at de mentalt følte sympati og empati med skuespillerne, slik at de glemte at de var i teateret. Uten forvarsel ble lyssettingen forandret, snorer, tau og rekvisita ble bevisst synliggjort eller skuespillerne henvendte seg direkte til publikum (sitter dere $\mathrm{OK}$ ?) Illusjonen av å se det virkelige liv raknet. Hensikten er at erkjennelse og selvforståelse skal erstatte innlevelse, empati.

\section{DIGITAL - MULTIMEDIAL}

Den siste postmoderne utstillingsformen, digital eller multimedial, utfordrer den ene imperative fortelling. Utstillinger på CD-ROM som Le Louvre, Vikinger og Kon-Tiki er fragmenterte og sammensatte. 


\begin{tabular}{|c|c|}
\hline Moderne & Postmoderne \\
\hline Lukket & Apen \\
3. persons fortolkning & 1. persons erfaring \\
Observatør & Deltaker \\
Aura & Simulacrum \\
Representasjoner av kultur, historie ... & Representasjoner av representasjoner \\
Kunnskap om ting & Kunnskap om publikum \\
En fortelling & Flere fortellinger \\
"vindu" & "speil" \\
\hline
\end{tabular}

I hypermedia er enhver lesning individuell og unik. Det skjer en vektforskyvning fra forfatter/kurator til publikum/bruker. Det aller siste innen moderne datateknologi, Virtual Reality eller simulacrumet par excellence, er for øvrig forkynt som «det glade budskap» som skal redde museet fra dets undergang, uten at "messias" har åpenbart seg ennå. Den objektorienterte utstillingen er $i$ alle fall spådd en snarlig død idet museet beveger seg fra å være gjenstandssamlinger til kultur- og informasjonssentra (Liestøl, 1994:48).

På bakgrunn i den inndelingen jeg har foretatt mellom moderne og postmoderne utstillingsformer har jeg listet opp noen forskjeller.

\section{SAMMENFATNING}

Den moderne utstillingen er lukket. Utstilleren har investert en foretrukken lesning, mens den postmoderne er åpen og pluralistisk. Mange forskjellige lesninger er mulig

Mens både Hazelius' og Rivers' samlinger baserte seg på 3. persons fortolkning, du måtte kjøpe den fortellingen som utstilleren hadde lagt ned i utstillingen, så ser vi en utvikling mot 1 . persons erfaring i postmoderne utstillinger. I Borg og Holocaust M. M. gir de inntrykk av at du personlig skal erfare hvordan det var i vikingtiden eller i utryddelsesleirene. Utstillingen er ikke bare en intellektuell eksersis, alle sansene skal aktiviseres. Det samme kan sies om Fluffs \& Feathers: du skal selv erfare på kroppen hvordan det er å få negative stereotypier tilskrevet seg selv. Publikum blir i større grad deltaker enn observatør.

De moderne utstillingene hadde en tiltrekningskraft i det de var i besittelse av ekte, autentiske gjenstander. Det var nærmest deres berettigelse, gjenstandenes aurakvalitet. Sentralt i det vi kan kalle postmoderne museumskultur er en slags «flerfronts-krig» mot aura eller det autentiske. Blant annet ved betydelig utvidelse av ting og historiske erfaringer som er vurdert verdig å havne på museum, f.eks. vanlige folks kultur som ikke har produsert "stor kunst» og masseproduserte forbruksvarer som i Fluffs \& Feathers. I det postmoderne museet er det reproduksjonen, kopien og simulacrumet som er beundret for genial ingeniørkunst eller sofistikert teknologi. Hologrammet av en vikinghjelm i The Jorvik Viking Center i York er jo mer beundret som en representasjon av vår teknologi, enn som et vitnesbyrd på fortidig liv. Museet reklamerer endog med at det har et ekte hologram. Det illustrerer på en utmerket måte Marshall McLuhans devise «the medium is 
72 the message». Det at publikum i det postmoderne museet er deltakere og vekten er lagt på interaksjon, underholdning og deltakelse utfordrer det moderne museets autentisitetsbegrep, hvor publikum i ærbødig stillhet skulle meditere over en endeløs rekke av sakrale, sjeldne og verdifulle objekt. Aura blir videre undergravet ved at museene i dag ofte avslører prosessen med å representere et objekt autentisk. De «aurabefengte» gjenstandssamlingene er dømt nord og ned, nå som simulacrumet eller hypervirkeligheten har gjort sitt inntog i museumsverdenen. Men Walter Benjamin tok feil når han hevdet at kunstverket mistet sin aurakvalitet i reproduksjonens tidsalder. "Solsikker» av Van Gogh er bare blitt mer verdt, desto flere kopier, plakater, postkort osv. som lages. Og kanskje er det slik at folk igjen vil oppleve den ekte vare når museet eventuelt blir gjennom-simulert?

De moderne utstillingene mente seg i stand til å gi en objektiv og sann framstilling av historien eller kulturer. Med postmodernismen flyter signifikanten rundt uten noen referent. Den kan utløse et ubegrenset antall meninger, og den meningen en person opplever er unik. Når referenten er fjernet blir virkeligheten eller historien overflødig. Ingen fortolkninger kan lenger bli objektivt demonstrert, inkludert utstillerens intensjoner. Så da kan vel ikke utstillingen være noe annet enn representasjoner av representasjoner? Fluffs \& Feathers prøver ikke si noe om indianere, snarere om representasjonene av indianere - hvordan de er skapt og reprodusert innenfor museet som institusjon.

Moderne utstillinger var fundert på kunnskap om ting, enten som enkeltobjekt eller satt i en kontekst. De var i alle tilfeller omdreiningspunktet. I postmoderne utstillinger ser det ut til at kunnskap om publikum er vel så viktig - kanskje viktigere. Fluffs \& Feathers handlet dypest sett om publikum. Museene i dag lager spørreskjema for å få tilbakemelding på utstillingene, og i noen tilfeller blir publikum direkte innvolvert $\mathrm{i}$ produksjonen av utstillinger. I de kulturhistoriske utstillingene er det ikke lenger bare historie, antropologi eller arkeologi som kommer til uttrykk, men også psykologi - persepsjon, hvordan folk tilegner seg kunnskap, og sosiologi - studier av publikums sammensetning og hvorfor de går på museum.

Som jeg allerede har vært inne på så er de moderne utstillingene grunnlagt på en enkeltstående imperativ, linear fortelling, mens ny, digital teknologi har egenskaper (hypertekst, multilinearitet, interaktivitet) som gjør dette vanskelig å opprettholde. Man får i stede mange små fortellinger. Den personlige 1. persons fortolkning innebærer dessuten at det nødvendigvis ikke finnes én mening, men mange.

Utstillingene, disse representasjonene, kan betraktes som vindu mot andre kulturer. Men ved nærmere ettersyn kan de også oppfattes som speil, som gjengir samtidens oppfatninger og vurderinger. 


\section{SUMMARY}

The Exhibition as Document

in Modern and Postmodern Times

The aim of this article is to focus on whether we can speak of modern and postmodern exhibitions as two separate categories. What are the main characteristics that separate the postmodern museum exhibition from its former counterpart? The concept of modernity has been perceived in several different ways from the 5th century $\mathrm{AD}$ up to the 20th century. Pitt Rivers published «The Evolution of Culture» in 1875 . Both this publication and his ethnographical exhibition in Oxford revealed how the concept of modernity had become Darwinist. Man (i.e. European man) had gradually reached higher levels of development, and linear arrangements of artefacts in vast rows (from primitive towards advanced) were intended to verify this Darwinist discourse. His Oxford exhibition can be considered as object-oriented.

A different approach to the modern museum exhibition characterized Artur Hazelius and his 'tableaux vivants'. His open air museum Skansen represented a new approach to the concept of modernity, since the attention was directed to the objects in a context rather than the objects isolated from any environment.

This essay argues that there are at least three different categories of postmodern museum exhibitions. One major difference between modernism and postmodernism is the lack in all three categories of any acknowledgement of aura-quality attached to a genuine original object. Postmodernism uses parody, mockery, sentimental nostalgia or whatever means are available in order to move the focus from the exhibits to the visitor.
The "Fluffs \& Feathers" exhibition hosted by the Royal Ontario Museum in 1992 is a typical example. This exhibition was aimed at the assumed prejudicies of the visitors concerning Indian cultures rather than at any attempt to describe Indian cultures as such.

At the Holocaust Memorial Museum in Washington DC the visitor is forced to identify with a holocaust victim. The distinction between representation and reality is reduced to an extent where it equals Jean Baudrillard's term 'simulacrum'.

A third postmodern way of exposing museum exhibits to the public is the digital or multimedial CD-ROM productions such as 'Le Louvre' or 'Kon-Tiki Interactive'. Through the extensive use of links and hypertext the one, singular, linear narrative becomes an impossibility. Each person's 'reading' will be unique.

\section{LITTERATUR}

Appignanesi/Garrant, Postmodernisme for begynnere. Nørhaven 1997

Baudrillard, Jean, Simulations. New York 1983

Bennet, Tony, The Birth of the Museum. History, Theory, Politics. London 1995

$\mathrm{B} ø$-Rygg, Arnfinn, Fra modernisme til postmodernisme. Ballade, årg.6, nr.2, 1982

Carlén, Staffan, Att ställa ut kultur. Om kulturhistoriska utställningar under 100 år. Stockholm 1990

Liestøl, Gunnar, Noen refleksjoner over interaktiv medieteknologi og museer. Museumsnytt 1/2 1994, s. 47-48

Liestøl, Gunnar, Notat om museet som massemedium. Nicolay 2/1988, s. 46-53

Macdonald/Fyfe (red.), Theorizing Museums. Representing identity and diversity in a changing world. London 1996

NOU 1996:7 Museum. Mangfald, minne, motestad. 
HILDE GAARD

74 Olsen, Bjørnar, Bilder fra fortida? Om museale representasjoner av de andre. Upubl. UITØ 1998

Pearce, Susan M. Museums, objects and collections: A Cultural Study. London 1992

Rajchman, John, Philosophical Events Essays of the '80s. New York 1991

Urry, John, Cultural change and contemporary holiday-making. Theory, Culture \& Society 5/1988, s. 35-55

Wilson, Tony, Reading the postmodernist Image: a "cognitive mapping». Screen 31(4) 1990, s. 390407

Hilde Gaard er cand.mag., holder for tiden på med hovedfag $i$ dokumentasjonsvitenskap ved Universitetet i Tromsø, med spesiell interesse for museumsutstillingen som en sarlig dokumentasjonsform.

Adr.: Stakkevollveien 27, N-9010 Tromso

e-mail: hilde.gaard@hum.uit.no 